Sharif University of Technology
Scientia Iranica
SCIENTIA
I RAN I CA
Transactions A: Civil Engineering
www.scientiairanica.com

\title{
Evaluation of the EDR performance in seismic control of steel structures using endurance time method
}

\author{
M.A. Foyouzat* and H.E. Estekanchi \\ Department of Civil Engineering, Sharif University of Technology, Tehran, P.O. Box 11155-9313, Iran.
}

Received 20 October 2014; received in revised form 2 August 2015; accepted 15 September 2015

\author{
KEYWORDS \\ Energy dissipating \\ restraint; \\ Endurance time \\ method; \\ Rigid-perfectly plastic \\ spectra; \\ Steel frames; \\ Performance-based \\ seismic rehabilitation.
}

\begin{abstract}
The Energy Dissipating Restraint (EDR) is a friction device which can be used to dissipate the energy introduced to a structure by a seismic event. In this paper, the performance of the structures which are equipped with the EDR is investigated in several intensity levels by using a novel seismic analysis method, namely the Endurance Time (ET) method. By reasonably estimating the response of structures over the entire range of the desired intensity levels through each time-history analysis, this method can effectively reduce the computational cost, offering an appropriate procedure for performance-based design of structures. The EDR performance in the seismic control of steel frames is evaluated at low to high intensity levels through three case studies with various story numbers. Additionally, a comparison is made between the ET results and those of conventional time-history analysis, in which a good agreement between the two methods is observed.

(C) 2016 Sharif University of Technology. All rights reserved.
\end{abstract}

\section{Introduction}

The "smart structure" concept has been applied in aerospace and mechanical industries for a long time. Application of this concept for wind and seismic response reduction of civil engineering structures is still a cutting-edge technology under research and development [1]. Basically, a smart structure can be designed by applying various types of structural control devices. The four well-known types of these devices are seismic isolation, passive, semi-active and active, as well as hybrid control systems. Passive devices have the virtue of being more economical and less complicated than other types of control devices.

Friction dampers are among typical passive energy dissipating systems. Friction is an efficient, reliable, and economical mechanism which can dissipate

*. Corresponding author. Tel.: +98 9197682329 E-mail addresses: mfoyuzat@hotmail.com (M.A. Foyouzat); stkanchi@sharif.edu (H.E. Estekanchi) kinetic energy by converting it to heat; so, it can be used to slow down the motion of buildings. The function of friction devices in a building is analogous to the function of the braking system in an automobile [2]. Based primarily on this analogy, Pall et al. [3] began the development of friction dampers to improve the seismic response of civil engineering structures. Some of the most conventional types of these devices are the X-braced friction damper [4], Sumitomo friction damper [5], Energy Dissipating Restraint (EDR) [6], and Slotted Bolted Connection (SBC) [7] to name but a few.

The focus of the paper in hand is on the performance of the EDR. EDR is a uniaxial friction damper which has been designed by Richter et al. [8]. The mechanics of this device are described in detail in [6] and [9]. The principal components of the device are internal spring, compression wedges, friction wedges, stops, and cylinder (Figure 1). Also, the variable parameters are the number of wedges, spring constant, gap, and spring precompression. The role of the 


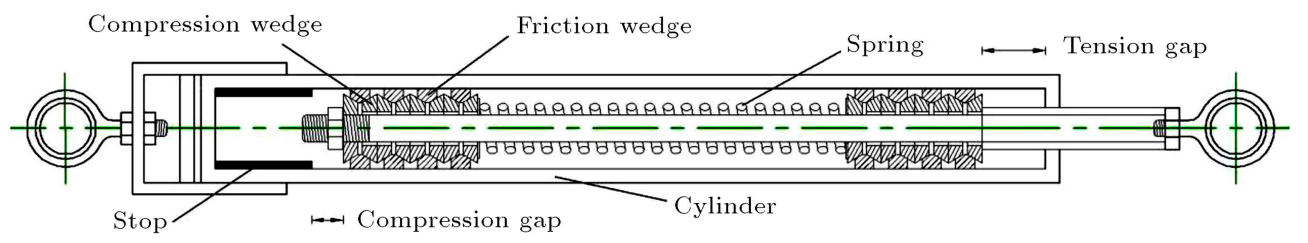

Figure 1. Configuration of the EDR.

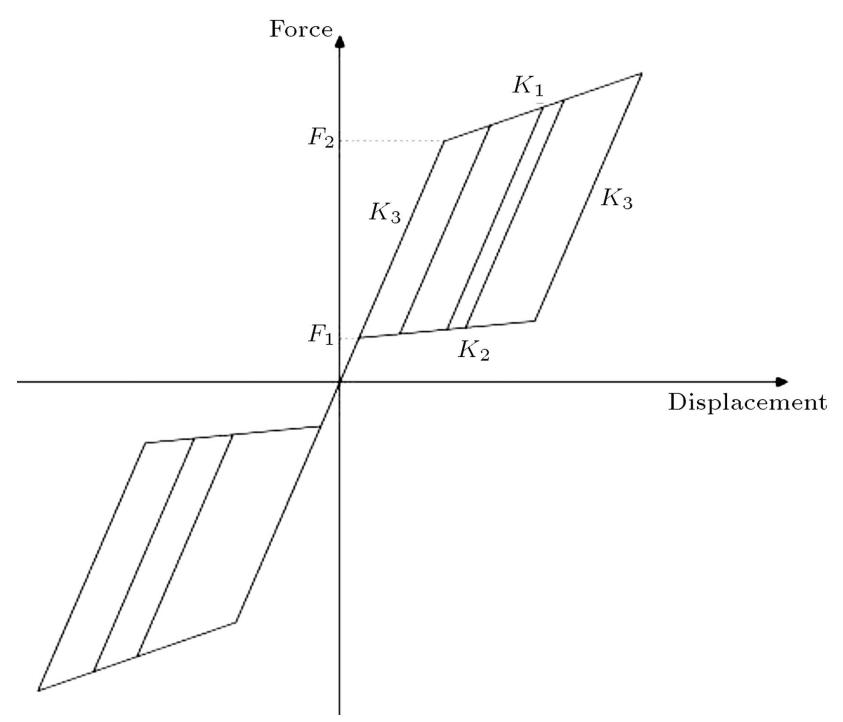

Figure 2. Double flag-shaped hysteretic loops of the EDR.

compression and friction wedges is to transmit and convert the axial force of the internal spring to a normal force on the cylinder wall.

The length of the spring can be variable through the operation of the device, which leads to a variable sliding friction. By adjusting the initial slip force and gap size, different hysteresis loops can be produced. With zero gaps and an initial slip force, the double flag-shaped loops, as is indicated in Figure 2, result. The parameters of the device are displayed in this figure. These double flag-shaped loops manifest the self-centering characteristic, that is, while unloading to zero, the device will return to its initial position without any residual deformations.

Several experimental studies have been carried out on the device, of which the results indicate the effectiveness of the EDR in reducing the seismic response of structures (e.g. $[8,10])$. The remarkable results are that the flag-shaped loops prove to be well-defined and quite consistent. Moreover, investigating cumulative energy time histories under earthquake signals implies that the frictional devices dissipate a significant portion of the total input energy.

The adequacy of the EDR has also been verified through manifold analytical studies (e.g. [9,11,12]). However, as noted by the researchers, hysteretic mechanisms do not respond quickly to sudden impulses. Additionally, higher modes were sometimes excited due to sudden stiffness changes associated with the frictional devices. These limitations notwithstanding, the EDR device consistently provided reductions in displacements and interstory drifts, and increased the effective damping ratio of the test structure.

One of the most outstanding properties of the EDR, when the device is adjusted to have zero gaps, is that it is self-centering. As mentioned earlier, in this case, the EDR demonstrates double flag-shaped hysteresis loops. This property has the merit of reducing the permanent deformations in buildings after severe earthquakes. No other friction damper enjoys this characteristic [13]. In fact, for the conventional friction dampers, which lack the self-centering property, significant permanent displacements could remain in the structure after the completion of the ground motion. This, in turn, brings about remarkable damage repair costs. From now on, wherever the EDR is mentioned in this paper, it refers to the device with double flag-shaped loops.

As a result of the absolutely nonlinear behavior of friction dampers, the use of the demanding nonlinear time-history method is inevitable for their analysis and design. In fact, the alternate simplified methods which have been authorized by the existing codes (e.g., nonlinear static and response spectrum procedures) are not reliable enough, on account of manifold simplifying postulations made in their development. Timehistory has the advantage of potentially being capable of directly including almost all sources of nonlinear and time-dependent material and geometric effects. Nevertheless, its traditional pitfall is being the most complex and time consuming procedure.

As is apparent from Figure 2, the hysteretic behavior of the EDR device exhibits high nonlinearity. Therefore, it is necessary to apply the nonlinear time history method for the performance-based analysis and design of the EDR-controlled structures. In the next section, a novel seismic analysis procedure, which is called the "Endurance Time (ET)" method, will be introduced. The ET method is not as much complicated and computational effort necessitous as the conventional time-history analysis. At the same time, it is not as much unreliable and approximate as the simplified methods. In fact, this method offers a more practical procedure for performance-based design of structures.

The present study investigates the application 
of the ET method in the performance-based seismic rehabilitation of steel frames by using the EDR devices. Three steel moment-resisting frames with different story numbers are considered as case studies. By applying the ET method, the performances of the frames before and after installing the EDR devices are compared with each other. Several engineering demand parameters (including interstory drift, plastic rotation of beams and columns, and absolute acceleration) are employed to this end. Furthermore, the maximum interstory drift responses are calculated once more through the nonlinear time-history analysis, using ground motions, and the results are compared with those from ET method.

\section{Basic concepts of the endurance time method}

Among various standard methods for the analysis of structures subjected to earthquake loadings, the nonlinear time-history analysis procedure is expected to produce the most realistic prediction of structural behavior. However, the complexity and high computational effort associated with this procedure have encouraged researchers to develop alternate analysis methods. These methods are much less complicated and can estimate the seismic demands with an acceptable degree of accuracy.

Endurance Time (ET) method is one of the significant types of these new methods, which is introduced by Estekanchi et al. [14]. This method is a time-historybased analysis procedure, in which the structure is subjected to a set of predesigned intensifying accelerograms referred to as Endurance Time Excitation Functions (ETEF's). The ETEF's are generated in such a way that their response spectra increase in time; hence, the response of the structure under this kind of excitation gradually increases with time [15]. In other words, each time in an ETEF is a representative of a record with a certain level of intensity (Figure 3 ). In the process of generating excitation functions, the ETEF's have been optimized to fit a specific target spectrum, which could be a codified spectrum or the
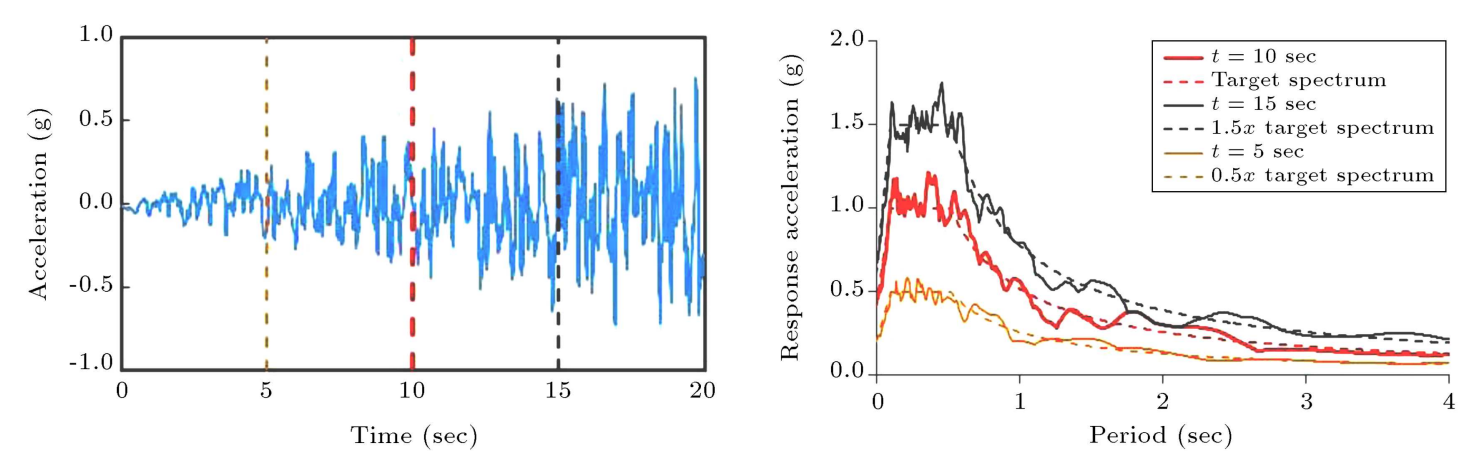

Figure 3. A typical ETEF and its response spectra at different times along with the target spectra. average spectrum of an ensemble of ground motions. In that process, the linear spectral acceleration of an ETEF is adjusted to satisfy Eqs. (1) and (2):

$$
\begin{aligned}
& S_{a}(T, t)=\frac{t}{t_{\text {target }}} S_{a C}(T), \\
& S_{u}(T, t)=\frac{t}{t_{\text {target }}} S_{u C}(T) \times \frac{T^{2}}{4 \pi^{2}},
\end{aligned}
$$

where $T$ is the free vibration period of the SDOF system; $t$ is the time in the ETEF; $S_{a}$ and $S_{u}$ are the ETEF's spectral acceleration and displacement spectra, respectively; $S_{a C}$ and $S_{u C}$ are the codified acceleration and displacement spectra, respectively; and $t_{\text {target }}$ is a predefined time (equals $10 \mathrm{sec}$ ) at which $S_{a}$ and $S_{u}$ coincide with $S_{a C}$ and $S_{u C}$, respectively [15]. The performance of the structure is estimated based on the time interval, during which it can sustain the imposed ETEF. By using a properly designed excitation function, this endurance can be correlated to the intensity level of ground motions that the intended structure can be expected to endure. More description on the concept of the ET method as well as the characteristics of the ET excitation functions can be found in literature (e.g., [14-16]).

The main advantage of the ET method over the regular time-history method, using ground motions, is that it needs a small number of analyses. In the ET method, the structural responses at different excitation levels are obtained in a single time-history analysis, thereby significantly reducing the computational demand. Accordingly, by using the ET method and regarding the concepts of performance-based design, the performance of a structure at various seismic hazard levels can be predicted in a single time-history analysis. This could be of great benefit when dealing with such problems as the performance-based optimum design of structures, wherein a huge computational effort is required even by employing the present-day high-speed computers [17]. The application of the ET method in the seismic performance assessment of steel frames has been studied by Mirzaee and Estekanchi [18] and Basim and Estekanchi [17]. 


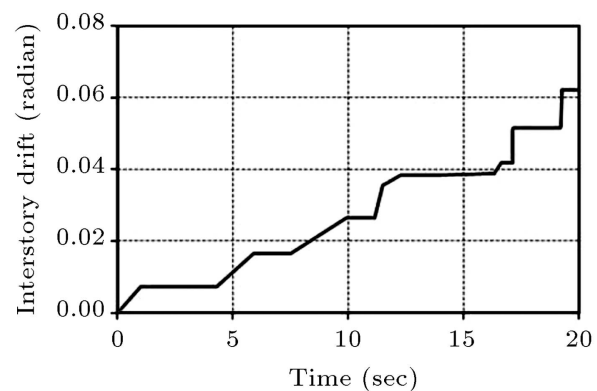

(a)

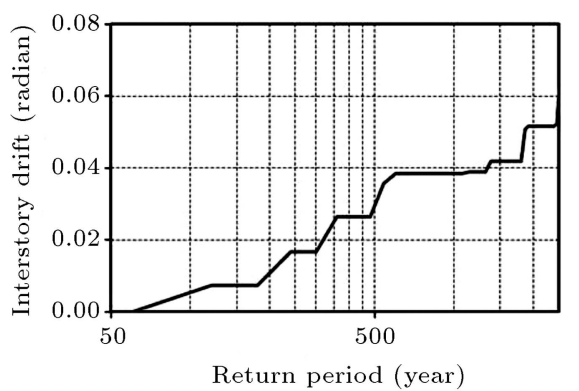

(b)

Figure 4. Sample ET response curve with horizontal axis in (a) time, and (b) return period.

The results of ET analysis are usually presented by increasing ET response curves. The ordinate at each time value, $t$, corresponds to the maximum absolute value of the required engineering demand parameter in the time interval $[0, t]$, as is expressed in Eq. (3):

$$
\Omega(P(t)) \equiv \max (|P(\tau)|) \quad \tau \in[0, t]
$$

In this equation, $\Omega$ is the Max-Abs operator as was defined above, and $P(t)$ is the desired response history such as interstory drift ratio, base shear, or other parameters of interest. The abscissa of an ET response curve is time, which is an indicator of the intensity in ET analysis. Figure 4(a) shows a typical ET response curve in which the maximum interstory drift is utilized as the demand parameter. ET curves are usually serrated, because of the statistical characteristics and dispersion of the results of the ET analysis in the nonlinear range. Sometimes the response value does not pass the maximum value experienced before in a time interval, and therefore the resulting ET curve has a constant value in that interval. In order to get more accurate and consistent ET curves, Estekanchi et al. recommended using the average of the results from three ET excitation functions [15].

Mirzaee et al. [19] originally investigated the correlation between time - as an indicator of the intensity in ET analysis - and seismic hazard return period. Substituting a common parameter, like the return period for time, increases the readability and efficiency of response curves and can considerably improve the presentation of ET analysis results. They utilized the elastic response spectrum defined in ASCE41-06 [20] as an intermediate criterion to establish this correlation.

Further investigations suggested that utilizing the elastic spectrum as the intermediate intensity measure to correlate the time and return period is not reliable in the cases in which the structures experience large nonlinear deformations $[21,22]$. Actually, in the structures which experience large nonlinear deformations, the difference between the results obtained by this procedure and the nonlinear time-history analysis, using ground motions, can be significant.
Foyouzat and Estekanchi [23] proposed using nonlinear Rigid-Perfectly Plastic (RPP) spectra in lieu of elastic response spectra to correlate the time in ET analysis and return period. The results suggested that the application of RPP spectra significantly improves the accuracy and reliability of the response curves resulted from ET analysis in nonlinear range compared with the procedures based on linear elastic spectra. As a result, regarding the high nonlinearity associated with the EDR device, as is discussed in the previous section, the RPP spectra are more appropriate intensity measures than the elastic spectra for the ET analysis of the structures equipped with EDR devices. In what follows, a brief explanation of this approach, which is discussed in detail in [23], is presented. An RPP system is a system possessing a force-displacement relationship, as is indicated in Figure 5. No deformation occurs until $F$ reaches the yield force, $F_{y}$, and the force cannot exceed the yield force, i.e. $|F| \leq F_{y}$. The RPP model can be simulated by a Coulomb friction block with a sliding friction force equal to $F_{y}$.

For a given earthquake excitation, the response of an RPP Single-Degree-Of-Freedom (SDOF) system depends only on the ratio $A_{y}=F_{y} / m$, where $m$ is the mass of the SDOF system. For a given ground motion, if maximum absolute displacements of RPP SDOF systems are calculated for a range of $A_{y}$ 's, the

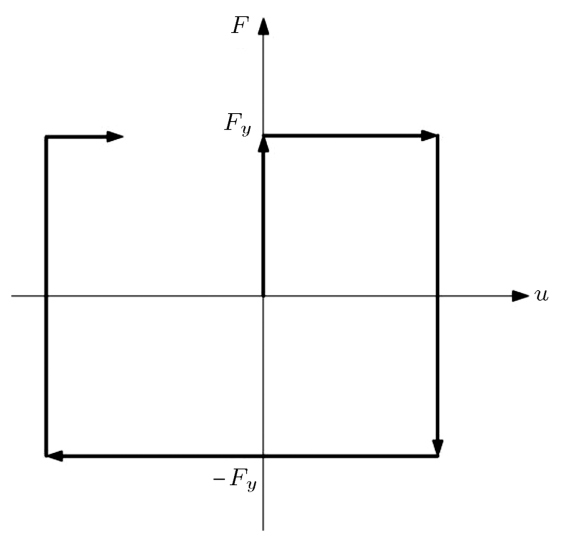

Figure 5. Force-displacement behavior of an RPP model. 
RPP spectrum of that ground motion will be provided. Furthermore, if the ground motion is scaled to a seismic hazard level corresponding to a specific return period, the resulted spectrum is the RPP spectrum corresponding to that return period. Besides this, one could obtain the RPP spectra of an ensemble of ground motions that are scaled to a specific return period and then use the average of those spectra as the RPP spectrum corresponding to that return period.

As is clear from the discussion above, the RPP spectrum is a function of two variables, namely the return period $(R)$ and $A_{y} / g$, that is to say $S_{\mathrm{RPP}}=$ $S_{\mathrm{RPP}}\left(A_{y} / g, R\right)$. Apart from this, the RPP spectrum for an ETEF is defined as is indicated in Eq. (4):

$$
S_{\mathrm{RPP}}\left(A_{y} / g, t\right)=\max (|\Delta(\tau)|) \quad \tau \in[0, t],
$$

where $t$ is time, and $\Delta(\tau)$ is the displacement of the RPP system at time $\tau$ due to an ETEF. If more than one ETEF is desired to be used (usually three, as pointed out earlier), the average spectra of those ETEF's can be applied. By acquiring the inverse of the function $S_{\mathrm{RPP}}$ with respect to $R$, return period can be written as $R=f\left(S_{\mathrm{RPP}}, A_{y} / g\right)$, where $f$ is a function that relates the return period to $S_{\mathrm{RPP}}$ and $A_{y} / g$. From Eq. (4), $S_{\mathrm{RPP}}=S_{\mathrm{RPP}}\left(A_{y} / g, t\right)$ of which the result would be Eq. (5):

$$
R=f\left(S_{\mathrm{RPP}}\left(A_{y} / g, t\right), A_{y} / g\right)=h\left(A_{y} / g, t\right),
$$

where $h$ is a function that relates the return period to $A_{y} / g$ and $t$. Since expressing function $h$ via a closed form formulation is not straightforward, this function can be evaluated in a range of $A_{y} / g$ 's and $t$ 's, and the values of $R$ can be stored in a matrix format as is done by Foyouzat and Estekanchi [23]. The ET time at which Eq. (5) holds is referred to as the equivalent time corresponding to return period $R$ and $A_{y} / g$.

In order to calculate the parameter $A_{y} / g$ of a structure, it is proposed to use the pushover curve resulted from a load pattern that is based on the first elastic mode shape. The effective yield force that is obtained from the pushover curve is divided by the mass of the structure to give parameter $A_{y}$. Having the return period and parameter $A_{y} / g$ of the structure, one can, using Eq. (5), readily get the ET equivalent time sought. After imposing an ETEF to the structure, the maximum absolute value of a desired response up to the equivalent time is calculated. If a set of ETEF's is considered, the average value is recorded as the response demand corresponding to the considered return period. This process is renewed for several return periods until the response curve of the structure is acquired. A typical response curve, which is produced in this way, is shown in Figure 4(b). The return period axis is plotted in a logarithmic scale.

\section{Modeling the EDR device in OpenSees}

OpenSees is one of the best pieces of software to model highly nonlinear macro-modeling problems. Thus, in this research, all nonlinear analyses are performed in OpenSees [24]. Unfortunately, there are no pre-defined materials in OpenSees which behave like EDR in loading and unloading phases. However, by assembling a few uniaxial materials, the EDR behavior can be modeled easily.

Let us consider the flag-shaped loops whose parameters are indicated in Figure 2. In order to model the flag-shaped behavior in OpenSees, one can combine a uniaxial element with linear elastic behavior and a uniaxial element with SMA behavior in parallel (Figure 6). The hysteretic behavior of an SMA uniaxial element in OpenSees together with the required parameters is displayed in Figure 7 . If the stiffness of the linear elastic element is set equal to $K_{2}$, the parameters of the SMA are given by Eqs. (6) through (9):

$$
\begin{aligned}
& E=K_{3}-K_{2}, \\
& \sigma_{s}^{A M}=\frac{\left(K_{3}-K_{2}\right) F_{2}}{K_{3}}, \\
& \sigma_{s}^{M A}=\sigma_{f}^{M A}=\frac{\left(K_{3}-K_{2}\right) F_{1}}{K_{3}},
\end{aligned}
$$

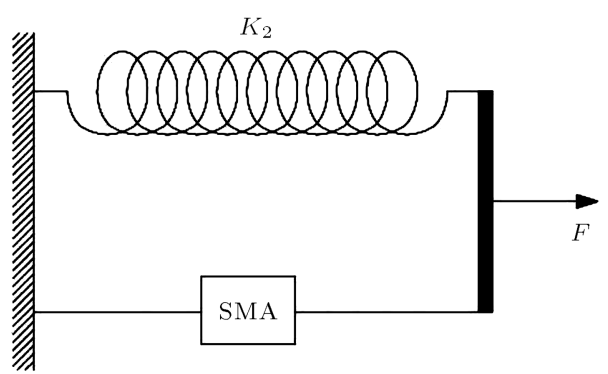

Figure 6. Modeling the EDR behavior in OpenSees.

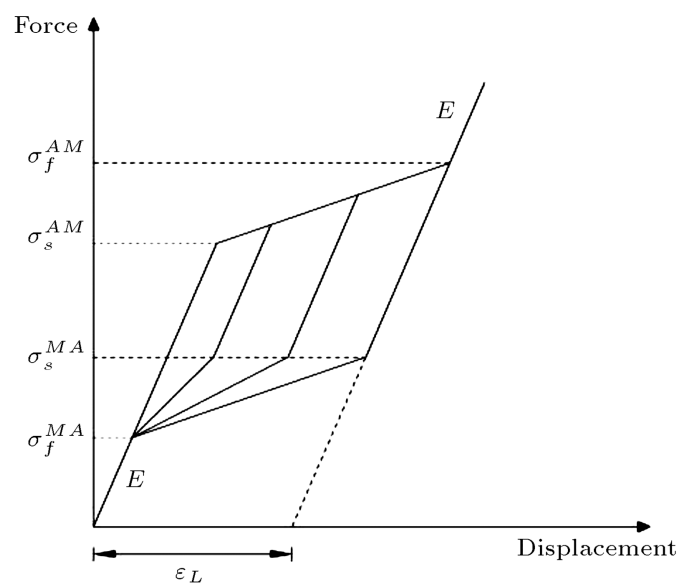

Figure 7. The hysteretic behavior of an SMA uniaxial element in OpenSees. 


$$
\sigma_{f}^{A M}=\frac{\left(K_{3}-K_{2}\right) F_{2}}{K_{3}}+\frac{\left(K_{1}-K_{2}\right)\left(K_{3}-K_{2}\right) \varepsilon_{L}}{K_{3}-K_{1}} .
$$

Since the hardening part of the SMA is not present in the EDR loops, the magnitude of $\varepsilon_{L}$ can be taken a very large value so that, actually, this point can never be reached in the numerical analyses. It has been observed that $F_{1}$ is not independent of other four parameters [9]. In fact, it can be shown that Eq. (10) holds between these five parameters of the EDR:

$$
F_{1}=\frac{K_{2}\left(K_{3}-K_{1}\right)}{K_{1}\left(K_{3}-K_{2}\right)} F_{2} .
$$

As a result, only four parameters are needed so as to completely model the EDR device.

\section{Performance assessment of EDR devices}

In this section, the effectiveness of the EDR devices in controlling the seismic response of structures is investigated by applying the ET analysis method. Three steel Moment Resisting Frames (MRF's) with different numbers of stories are addressed as the case studies. The set under investigation consists of twodimensional frames with 3,6 , and 10 stories and three bays which are built on a site in Los Angeles region with soil class C, as is defined in ASCE41-06 [20]. The height of all stories is $3.2 \mathrm{~m}$ and the bay width is $5.0 \mathrm{~m}$. Some basic properties of these frames are summarized in Table 1. In this table, parameter $A_{y} / g$ is calculated according to the procedure that is explained in Section 2.

The supports of 3St and 6St frames are assumed to be fixed, while hinged supports are considered for

Table 1. Properties of the initial frames in summary.

\begin{tabular}{cccc}
\hline Property & $\mathbf{3 S t}$ & $\mathbf{6 S t}$ & $\mathbf{1 0 S t}$ \\
\hline $\begin{array}{c}\text { Mass participation } \\
\text { (mode 1) }\end{array}$ & $81 \%$ & $77 \%$ & $78 \%$ \\
$\begin{array}{c}\text { Fundamental period, } \\
T_{1}(\mathrm{sec})\end{array}$ & 0.97 & 1.24 & 1.6 \\
$A_{y} / g$ & 0.24 & 0.17 & 0.23 \\
\hline
\end{tabular}

10St frame. The first story of frame $6 \mathrm{St}$ is assumed to be surrounded by a concrete retaining wall, which binds it to have similar lateral displacements to the ground at any time. As a result, the base level of this frame is transferred to the level of the first story. Further information on the geometry as well as the section properties of the frames can be found in [25]. These structures are designed by applying only a fraction of the codified design base shear per INBC code [26] - which is quite consistent with AISC-ASD building code [27] - so that the structures will require rehabilitation by using EDR devices. Additionally, it is assumed that, for practical reasons, the owner has constrained the installation of the EDR's to only one bay in each story.

Table 2 describes the ground motions employed in the current study. All of these ground motions are recorded on soil type $\mathrm{C}$. The scale factor for each ground motion, corresponding to return period, $R$, is selected so that the 5 percent damping linear elastic spectrum of the ground motion between $0.2 T$ and $1.5 T$ will not fall below the codified spectrum (corresponding to return period, $R$ ) in the same range, where $T$ is the fundamental period of the structure being analyzed. The codified spectrum corresponding to any return period is formulated in ASCE41. After the calculation of the scale factors, the average RPP spectrum corresponding to each return period can be obtained. For example, the RPP spectra for these ensemble of ground motions scaled to the return period of 475 years for $T=1 \mathrm{sec}$ together with their average are represented in Figure $8(g$ is the acceleration of gravity).

The ETA20inx01-3 series, generated with the duration of 20 seconds, is used as ETEF's. More information on different ETEF series is publicly available on Endurance Time Method website [28]. The RPP spectrum for each ETEF can be acquired by applying Eq. (4). Equivalent times can now be calculated through using Eq. (5) and, at last, by pursuing the procedure explained in Section 2, the ET response curves can be achieved. The provisions of ASCE41-06 are applied for performance-based design and check of

Table 2. Description of the groundmotions used in this study.

\begin{tabular}{cccccc}
\hline $\begin{array}{c}\text { ID } \\
\text { no. }\end{array}$ & Year & $\begin{array}{c}\text { Earthquake } \\
\text { name }\end{array}$ & Station & $\begin{array}{c}\text { Component } \\
(\mathbf{d e g})\end{array}$ & $\begin{array}{c}\text { PGA } \\
(\mathbf{g})\end{array}$ \\
\hline 1 & 1999 & Kocaeli, Turkey & Arcelik & 0 & 0.22 \\
2 & 1976 & Friuli, Italy & Tolmezzo & 0 & 0.35 \\
3 & 1995 & Kobe, Japan & Nishi-Akashi & 0 & 0.51 \\
4 & 1999 & Hector Mine & Hector & 90 & 0.34 \\
5 & 1986 & Palm Springs & Fun Valley & 45 & 0.13 \\
6 & 1979 & Imperial Valley & El Centro, Parachute Test & 315 & 0.20 \\
7 & 1984 & Morgan Hill & Gilroy \#6, San Ysidro & 90 & 0.28 \\
\hline
\end{tabular}




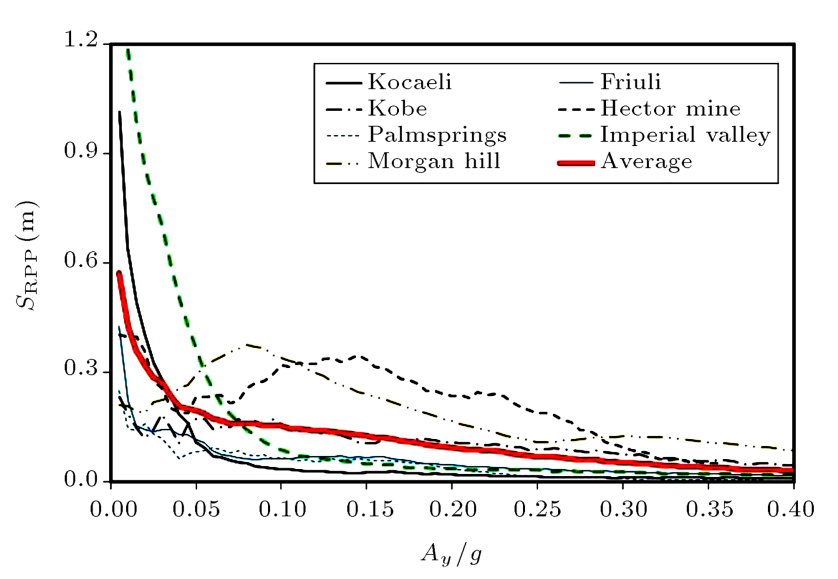

Figure 8. The RPP spectra of an ensemble of scaled ground motions together with their average.

the structures. The rehabilitation objective is selected as Enhanced Objectives - $k, p$, and $b-$ as is defined in ASCE41-06.

Before getting down to the analysis of the three aforementioned frames, it is worth introducing two useful definitions, which were originally proposed by Mirzaee and Estekanchi [18]. These definitions could be employed in order to facilitate the evaluation of the seismic performance of structures by using the ET method. The first definition is referred to as the Damage Level (DL) index, which is a normalized continuous numerical value, as is defined by Eq. (11). The DL is a dimensionless index which creates a numerical presentation for the performance levels (values of 1,2 , and 3 for IO, LS, and CP levels, respectively).

$$
\mathrm{DL}=\sum_{i=1}^{n} \frac{\max \left\{\theta_{i-1}, \min \left(\theta, \theta_{i}\right)\right\}-\theta_{i-1}}{\theta_{i}-\theta_{i-1}}
$$

In this equation, $\theta$ is the parameter that should be computed from the analyses and checked as per codes in order to evaluate the seismic behavior of the structure. The parameter $\theta$ can be a representative of the plastic rotation in beams, the plastic rotation in columns, or any other significant response parameter for which limiting values as per codes have been adopted. Additionally, $n$ is the number of performance levels considered in the design ( $n=3$ in this study). The parameters $\theta_{i}$ are the ASCE41-06 limiting values at each performance level, and $\theta_{0}$ is always set equal to zero. It should be noted that the DL index is not a new response parameter in addition to those addressed in ASCE41 for the evaluation of structures. It is only a new form of representing the responses, which is proposed for use in the ET method. Moreover, utilizing the DL index facilitates the combination of different parameters that are involved in assessing the seismic performance of a structure. The second definition is referred to as the target curve. The target curve specifies maximum acceptable responses at various

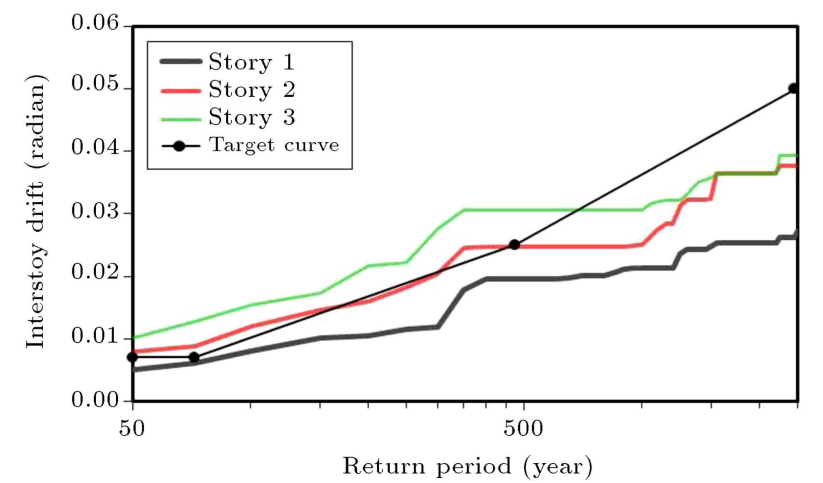

(a)

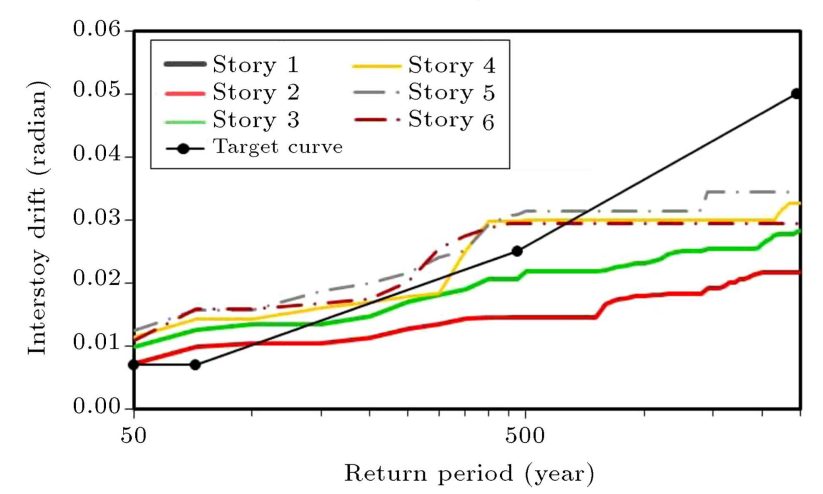

(b)

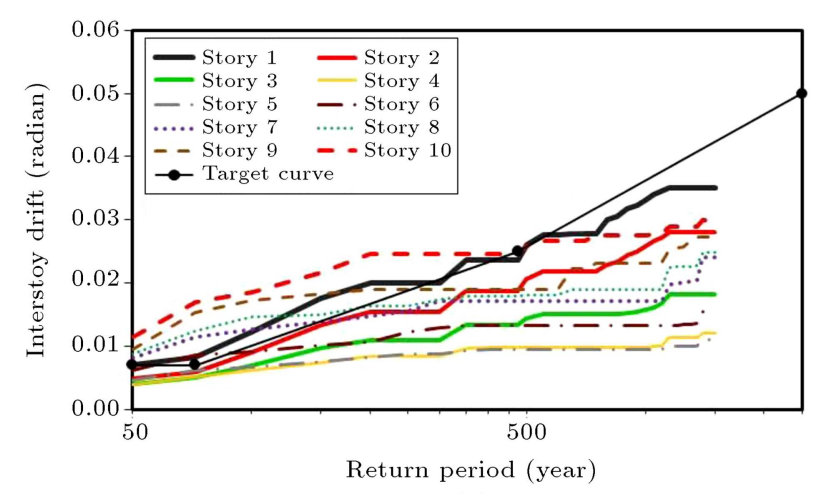

(c)

Figure 9. Interstory drift response curves for (a) 3St, (b) 6 St, and (c) 10St frames.

damage levels as a continuous curve [18]. By comparing the ET performance curve with the target curve, the seismic performance of the structure at different seismic intensities can be evaluated.

Figures 9 through 12 illustrate the interstory drift, plastic rotation of columns, plastic rotation of beams, and absolute acceleration response curves obtained for the foregoing frames, respectively. According to the ASCE41 provisions, the limiting values for the plastic rotation of beams depend on the section properties, while for the plastic rotation of columns, they depend on both the section properties and the axial force of the columns. Hence, the plastic rotations are represented in terms of the DL index in order to avoid multiple target curves and streamline the presentation 


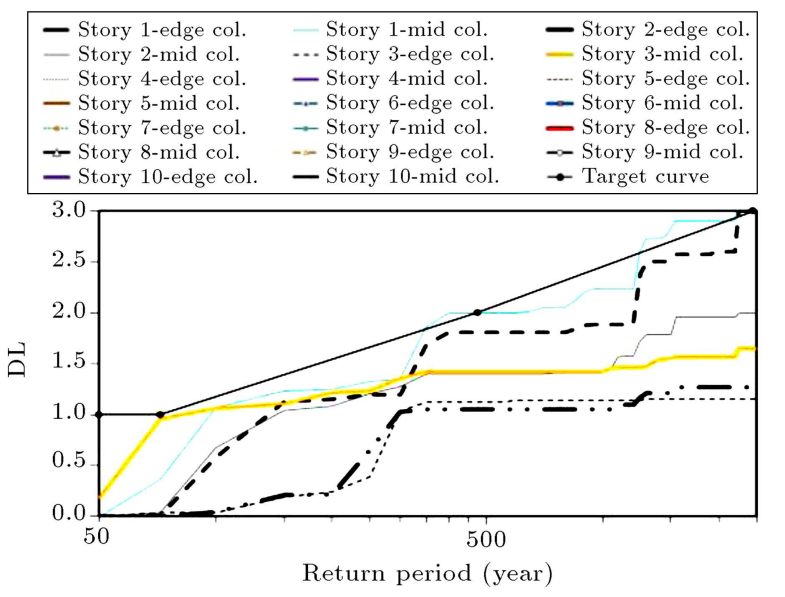

(a)

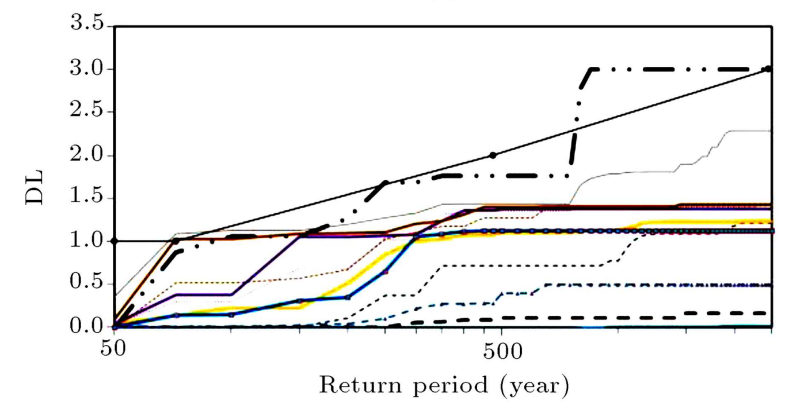

(b)

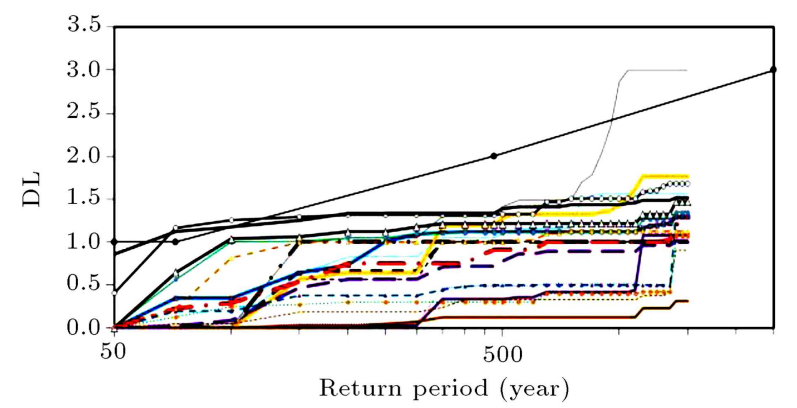

(c)

Figure 10. Column rotation response curves for (a) 3St, (b) 6 St, and (c) 10St frames.

of the diagrams. Since no acceptance criterion for the absolute acceleration has yet been established in ASCE41, the target curve is absent from the absolute acceleration diagrams. For the 10-story frame, the response curves are shown up to the 1500 -yr return period. The reason is that the duration of ETA20inx013 series (20 seconds) is not sufficient to cover all the return periods of interest. Generating ETEF's with longer durations can resolve this shortcoming.

According to ASCE41-06, if the axial force to $P_{C L}$ (the lower bound axial column strength) ratio of a column falls below 0.5 , only the column rotation needs to be checked, and there is no need to check the axial force-bending moment interaction equation. As was observed in all the results of this study, in no column did this ratio exceed 0.5 ; thus, checking

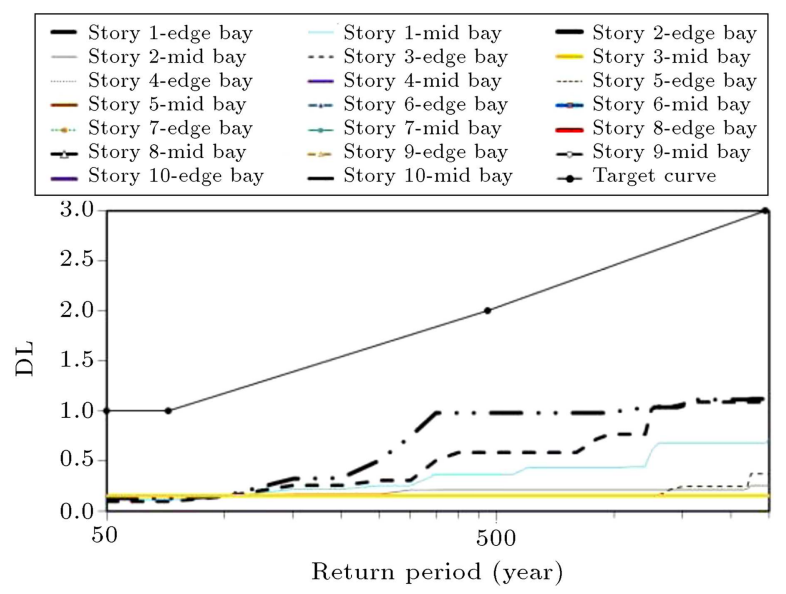

(a)

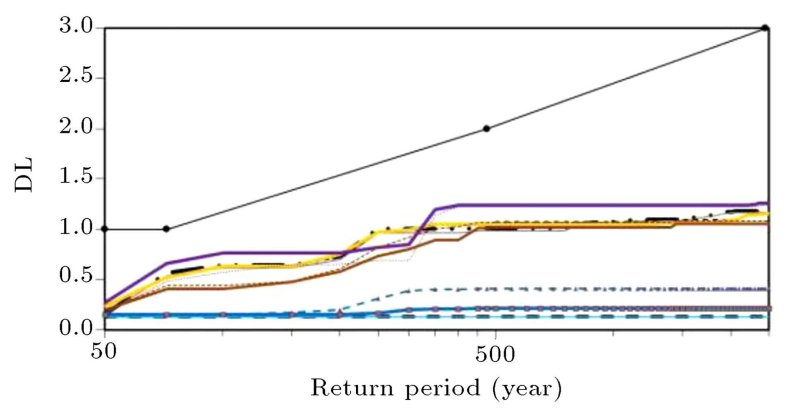

(b)

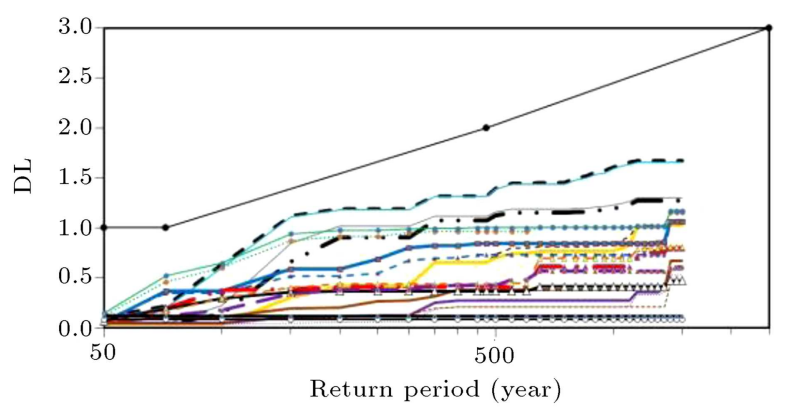

(c)

Figure 11. Beam rotation response curves for (a) 3St, (b) $6 \mathrm{St}$, and (c) 10St frames.

the interaction equation is no longer necessary. It is discernible from the response curves that the drifts and column rotations exceed the target curve in some cases, and the structures need to be rehabilitated. To this end, EDR dampers are to be employed to control the seismic response of the structures. In the middle bay of each story, two identical EDR devices are installed in the form of cross bracings. The properties of each device are selected by trial and error until an acceptable response is achieved.

At each stage of the trial and error process, the fundamental period and parameter $A_{y} / g$ of the rehabilitated structure are calculated. By doing so, the equivalent times are obtained, which must be employed to acquire the ET response curves, as was previously explained. The $A_{y} / g$ parameter does not significantly 


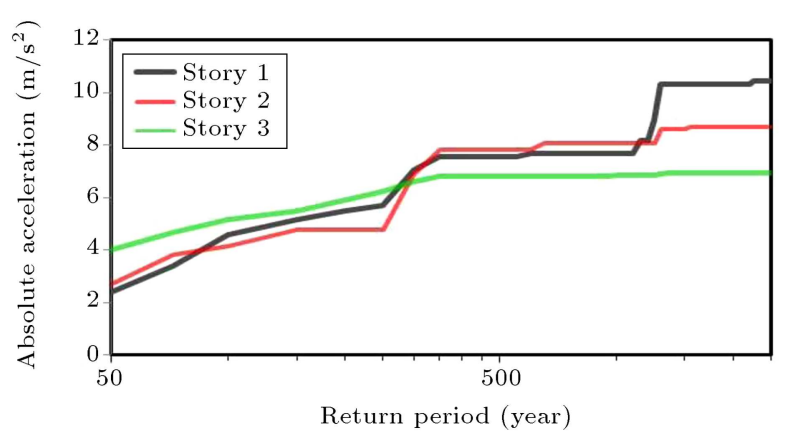

(a)

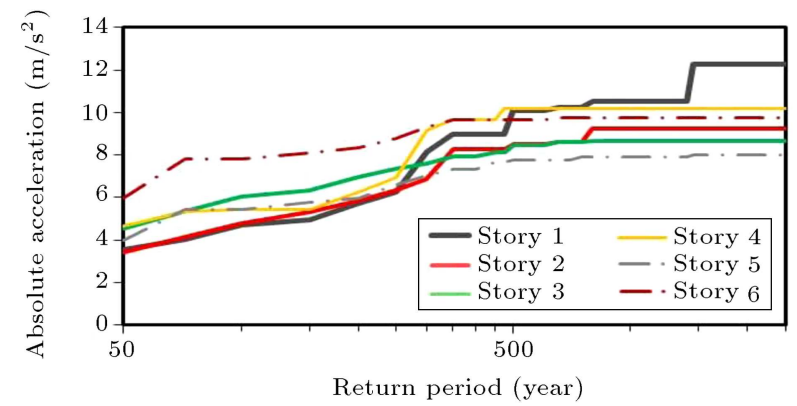

(b)

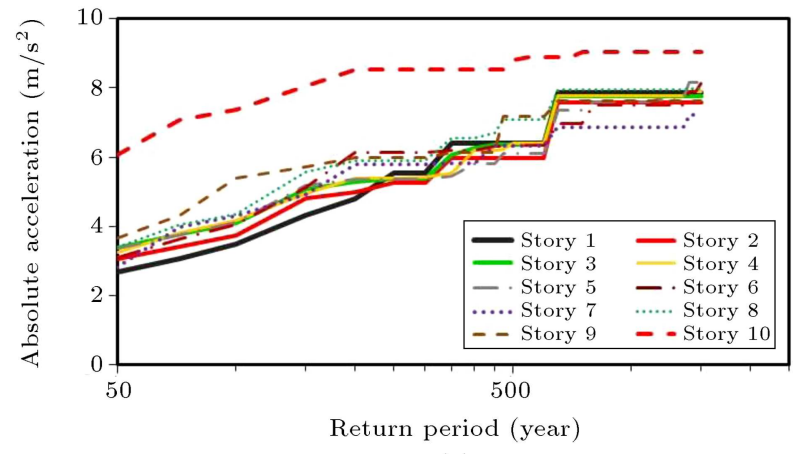

(c)

Figure 12. Absolute acceleration response curves for (a) $3 \mathrm{St}$, (b) 6St, and (c) 10St frames.

vary through stages, thanks to the relatively small stiffness of EDR devices. Therefore, the equivalent times undergo trivial changes at each stage, as compared to the preceding stages. As a result, one can use the same $A_{y} / g$ of the initial structure for the ensuing stages to avoid performing a separate pushover analysis for each stage. After reaching an acceptable response, a pushover analysis can be performed to obtain the exact $A_{y} / g$ of the last stage and reproduce the response curves. This procedure effectively reduces the designing time.

The characteristics of each device at the end of the trial and error process, together with the parameters of the rehabilitated frames - referred to as 3St-EDR, 6StEDR, and 10St-EDR - are summarized in Table 3 . The resulted response curves of the rehabilitated frames are shown in Figures 13 through 16. As can be inferred from these figures, EDR devices have significantly reduced the drifts and column rotations of the structures

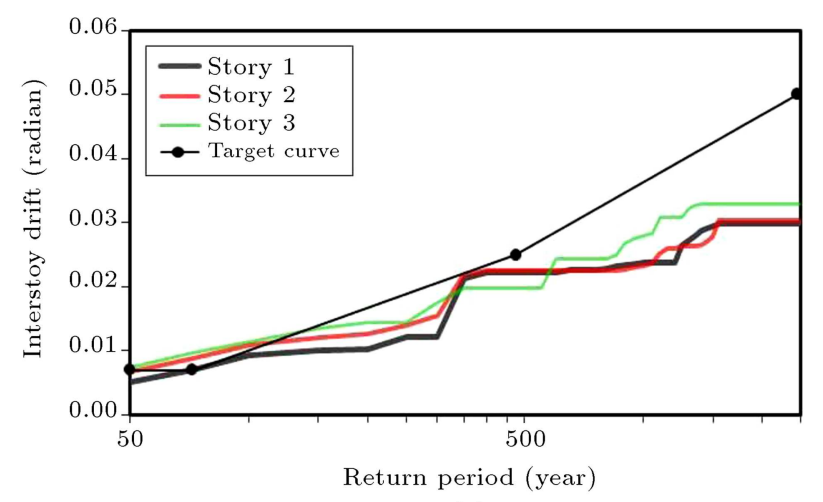

(a)

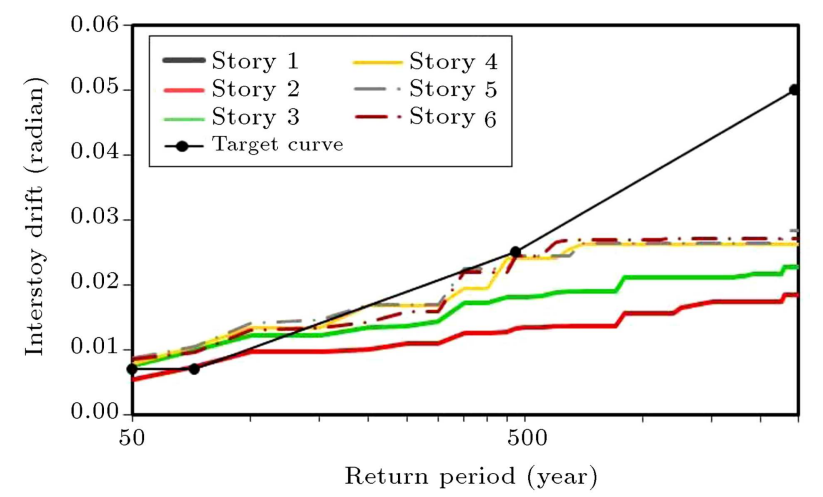

(b)

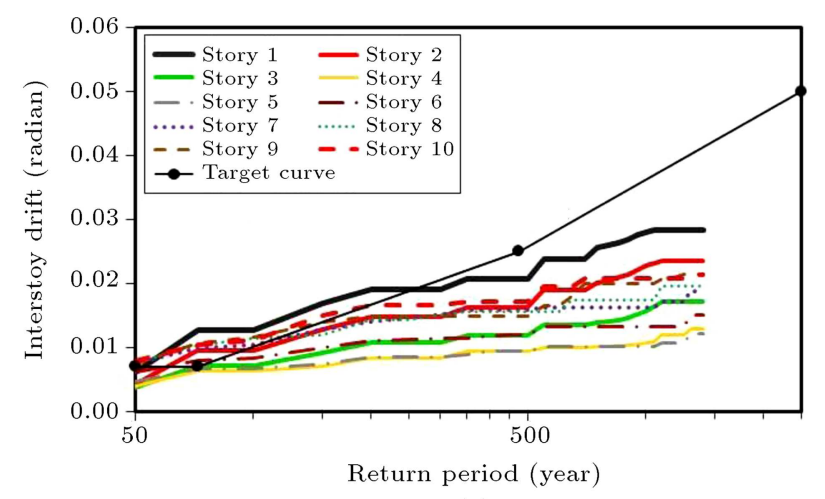

(c)

Figure 13. Interstory drift response curves for (a) 3St-EDR, (b) 6St-EDR, and (c) 10St-EDR frames.

in large and medium return periods, which correspond to moderate and strong ground motions, respectively.

Despite this, there is only a slight reduction in small return periods, and the interstory drift response curves do not completely fall below the target curve in this range. The main reason is that, in small events, few hysteresis loops develop, and a small amount of energy is dissipated. However, in medium and large return periods, the formation of quite a few loops dissipates a large amount of energy, which causes the responses to be considerably mitigated. Even by increasing the slip forces $\left(F_{2}\right.$ 's) of the devices, the responses do not effectively improve in small return periods. Similarly, the use of a higher initial stiffness 
Table 3. Properties of the rehabilitated frames in summary.

\begin{tabular}{|c|c|c|c|c|c|}
\hline $\begin{array}{c}\text { Frame } \\
\text { name }\end{array}$ & $\begin{array}{c}\text { EDR } \\
\text { location }\end{array}$ & $\begin{array}{c}K_{1} \\
(\mathbf{k N} / \mathbf{m})\end{array}$ & $\begin{array}{c}\boldsymbol{K}_{\mathbf{2}} \\
(\mathrm{kN} / \mathrm{m})\end{array}$ & $\begin{array}{c}K_{\mathbf{3}} \\
(\mathrm{kN} / \mathrm{m})\end{array}$ & $\begin{array}{c}F_{2} \\
(\mathrm{kN})\end{array}$ \\
\hline 3St-EDR & 1st story & 1338.8 & 17.8 & 13388.2 & 60.0 \\
\hline$T_{1}=0.85 \mathrm{sec}$ & 2nd story & 1338.8 & 17.8 & 13388.2 & 60.0 \\
\hline$A_{y} / g=0.26$ & 3rd story & 964.0 & 17.8 & 9639.6 & 40.1 \\
\hline \multirow{5}{*}{$\begin{array}{c}6 \text { St-EDR } \\
T_{1}=1.13 \mathrm{sec} \\
A_{y} / g=0.19\end{array}$} & 2nd story & 1606.6 & 17.8 & 16065.9 & 60.0 \\
\hline & 3rd story & 1338.8 & 17.8 & 13388.2 & 60.0 \\
\hline & 4th story & 1606.6 & 17.8 & 16065.9 & 60.0 \\
\hline & 5th story & 1071.0 & 17.8 & 10710.6 & 60.0 \\
\hline & 6 th story & 428.4 & 17.8 & 4284.2 & 40.1 \\
\hline \multirow{10}{*}{$\begin{array}{c}10 \text { St-EDR } \\
T_{1}=1.51 \mathrm{sec} \\
A_{y} / g=0.24\end{array}$} & 1st story & 4819.8 & 17.8 & 48197.6 & 50.0 \\
\hline & 2nd story & 2142.1 & 17.8 & 21421.2 & 50.0 \\
\hline & 3rd story & 2409.9 & 17.8 & 24098.8 & 50.0 \\
\hline & 4th story & 1499.5 & 17.8 & 14994.8 & 40.0 \\
\hline & 5 th story & 1071.1 & 17.8 & 10710.6 & 40.0 \\
\hline & 6 th story & 1071.1 & 17.8 & 10710.6 & 40.0 \\
\hline & 7th story & 1285.3 & 17.8 & 12852.7 & 50.0 \\
\hline & 8th story & 1285.3 & 17.8 & 12852.7 & 50.0 \\
\hline & 9 th story & 1285.3 & 17.8 & 12852.7 & 50.0 \\
\hline & 10th story & 1285.3 & 17.8 & 12852.7 & 50.0 \\
\hline
\end{tabular}

is not useful, since this will increase the axial force demand of the damper, which causes the device to fail.

It is worth noting that the interstory drift acceptance criteria stipulated in ASCE41-06 are recommended values only, and it is not imperative for a structure to satisfy them. In fact, if a design can meet the beam and column plastic rotation acceptance criteria (and, if necessary, the axial force-bending moment interaction effect), it is rated as an acceptable design. Accordingly, the designs of the rehabilitated frames are quite acceptable, regarding the performance objectives.

Referring to the foregoing results, it could be concluded that if it is desired to provide additional damping for a range of moderate and large earthquakes, the EDR device is an apt choice. This would be the case, provided that the building performance for small events is satisfactory, and also limiting the device force is important. Through applying the time-history analysis method on a range of SDOF structures, Nims et al. [6] drew a similar conclusion for SDOF systems. By using a more affordable ET method, the current study has verified this result for real multi-story frames.

Figures 12 and 16 display the absolute acceleration response curves of the foregoing frames, before and after the rehabilitation, respectively. The absolute acceleration is among those parameters which play an important role in the nonstructural damage, the life cycle cost due to the loss of contents [29], and the occupants' comfort [30]. Generally, moment-resisting frames have acceptable values for absolute acceleration, while the absolute accelerations in braced frames are large. As can be observed from Figures 12 and 16, the installation of the EDR devices has not significantly increased the absolute accelerations compared to those of the initial structures. This result reveals one of the advantages of these devices. The reason for this behavior lies in the relatively small stiffness of the EDR's as well as the energy absorption due to their operation during the earthquake.

As stated previously, as far as the absolute acceleration is concerned, no acceptance criterion has been stipulated in ASCE41-06. However, several researchers have proposed limiting values for the absolute acceleration at different performance levels. For example, according to Elenas and Meskouris [29], for the IO, $\mathrm{LS}$, and CP levels, the corresponding limiting values are $2.0,9.8$, and $12.5 \mathrm{~m} / \mathrm{s}^{2}$, respectively. Figure 16 suggests that, except for the small return periods, the absolute accelerations satisfy the above limitations.

\section{Comparative study}

In this section, a comparative study is carried out between three different methods of analysis, namely 


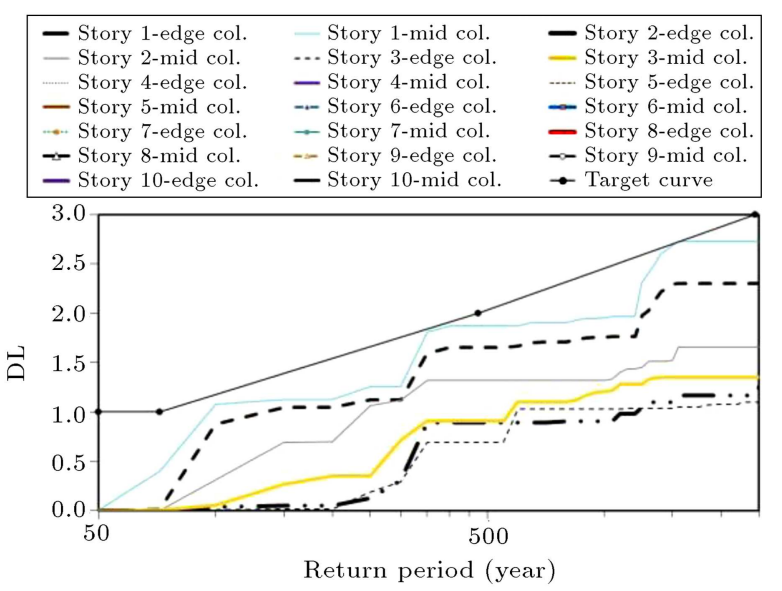

(a)

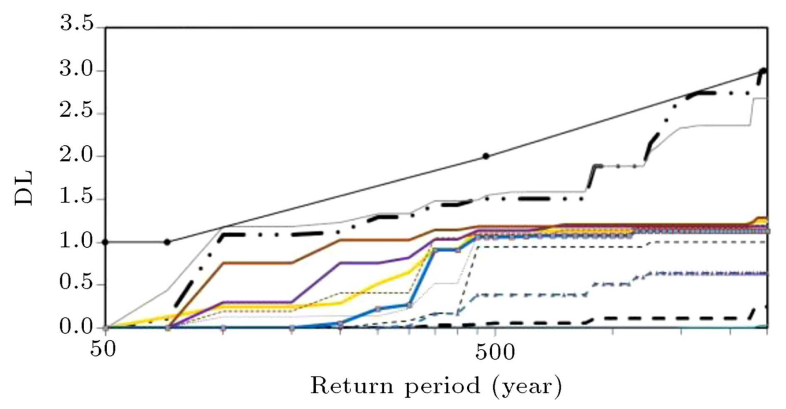

(b)

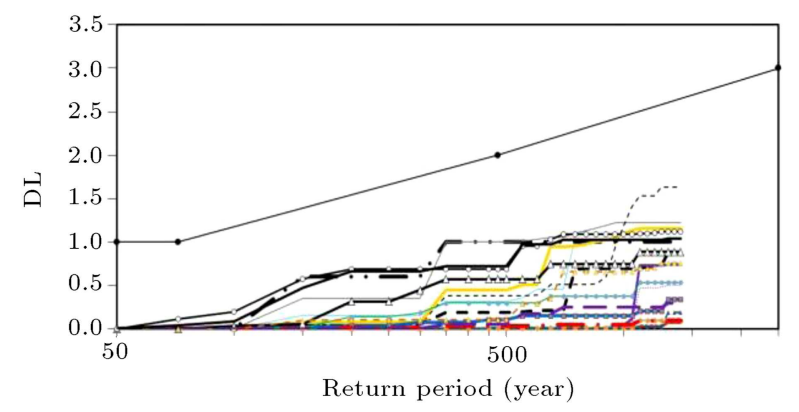

(c)

Figure 14. Column rotation response curves for (a) 3St-EDR, (b) 6St-EDR, and (c) 10St-EDR frames.

time-history analysis, ET method based on RPP spectra, and ET method based on elastic spectra. The results of the second method were obtained in the previous section. The last method, as was discussed in the preceding sections, utilizes the elastic spectra as the intermediate intensity measure to correlate the time and return period. A detailed description of this method can be found in the study accomplished by Mirzaee et al. [19]. Apart from this, the time-history analysis is performed by using the ground motions described in Table 2. The maximum interstory drift responses of the aforementioned frames are calculated via these three methods in a number of return periods, some results of which are displayed in Figure 17. Note that the time-history responses in Figure 17 are based on the average of the maximum absolute values

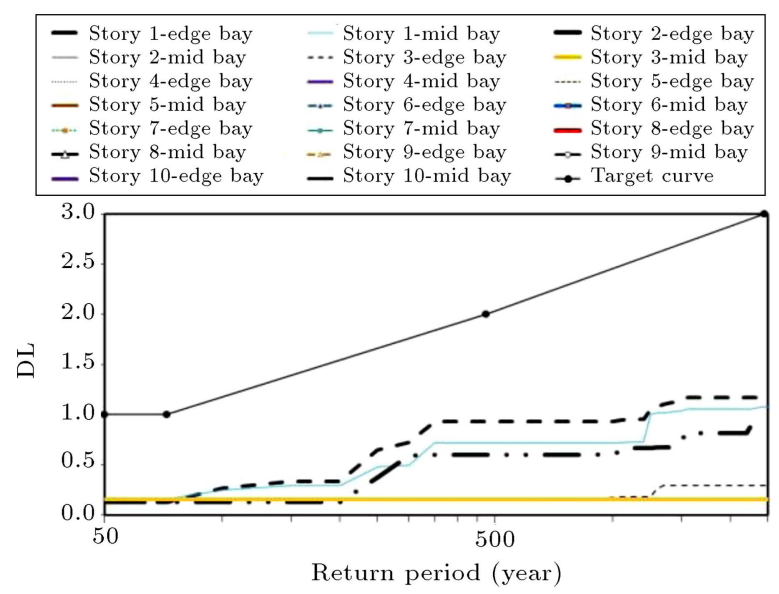

(a)

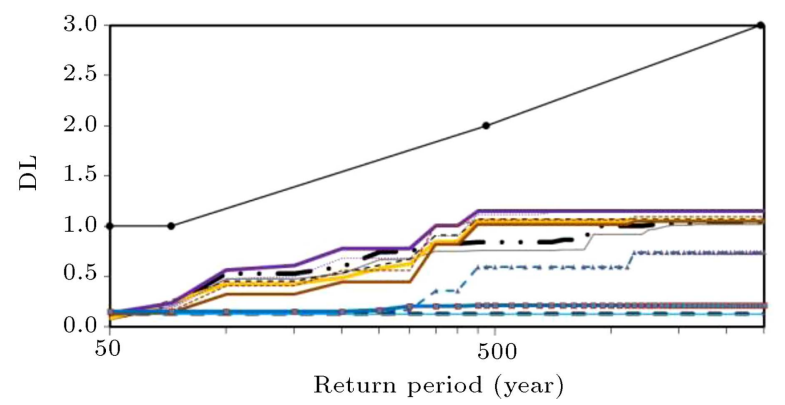

(b)

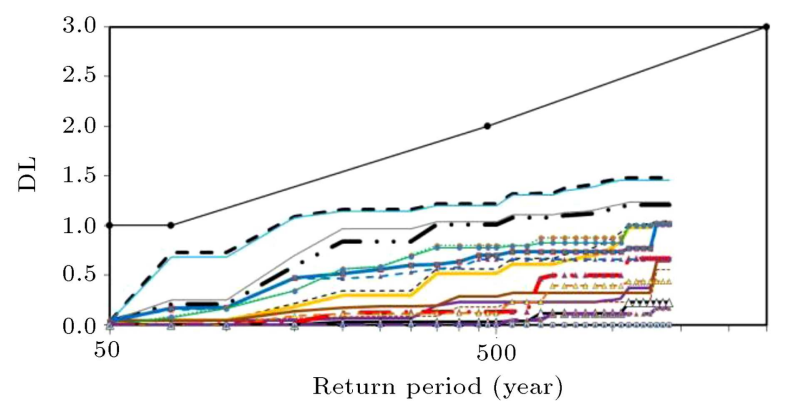

(c)

Figure 15. Beam rotation response curves for (a) 3St-EDR, (b) 6St-EDR, and (c) 10St-EDR frames.

resulted from the analyses over the considered ground motions.

Figure 17 suggests that in medium and large return periods (i.e., return periods greater than 475 years), the results of the ET method based on RPP spectra are in good agreement with the results of the time-history analysis. In addition, the trends of the diagrams are well predicted by the ET method. This stems from the fact that the frames experience significant inelastic displacements at these return periods. However, in small return periods, the frames experience slight plastic deformations. Therefore, in small return periods, the ET method that is based on elastic spectra yields a better result, although the RPP spectra-based method is still a good approximate. Basically, these observations are in line with the results reported in [23]. 


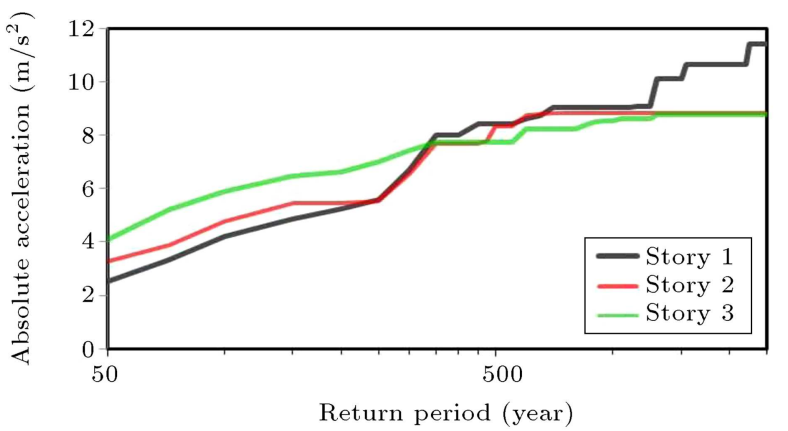

(a)

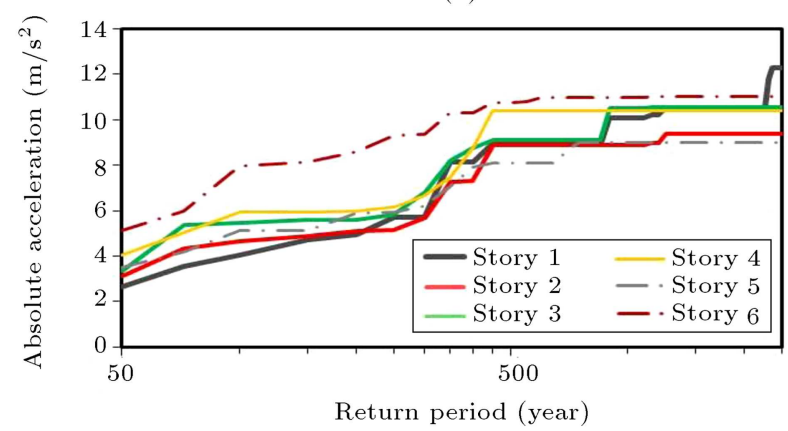

(b)

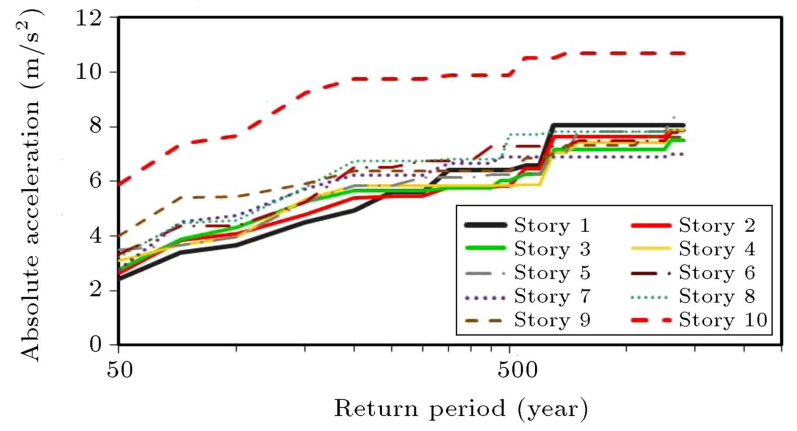

(c)

Figure 16. Absolute acceleration response curves for (a) 3St-EDR, (b) 6St-EDR, and (c) 10St-EDR frames.

By making a further inspection of Figure 17, a change in curvature in the interstory drift diagrams is observed for the 10-story frame as compared with those of 3- and 6-story frames, which could be justified as follows. Owing to the hinged supports that have been assigned to the 10-story frame, the lateral stiffness of the first story is relatively small, so that the interstory drift of the first story caused by an earthquake excitation may be greater than that of succeeding stories. This, in turn, gives rise to the aforementioned change in curvature. Moreover, this observation has been corroborated through examining the first and second mode shapes of the 10-story frame and the resulting drifts.

It should be noted that the RPP model has zero plastic phase slope, while the slope of the second portion of the EDR devices is a non-zero value (see Figure 2). Additionally, the hysteresis loops of the EDR devices are completely different from the loops of the RPP materials. Apart from this, the inherent dispersion of the results of the ET method can be another important source of error. In spite of these important differences, the results of the ET method based on RPP spectra, as previously observed, show an acceptable degree of accuracy. Moreover, the ET results are conservative in quite a few cases.

It is of value to point out that, in the time-history method, the structural responses were generated by using seven ground motions at three return periods, requiring 21 time-history analyses. On the other hand, generating the responses by the ET method required only 3 time-history analyses, which is about $15 \%$ of the computational effort as compared to the conventional time-history method. Furthermore, if it were needed to calculate the responses in more than three return periods, the required number of the analyses in the time-history method would increase proportionally. However, the number of analyses remains the same (i.e., just three analyses) when the ET method is utilized.

\section{Summary and conclusion}

In this study, the application of the ET method in the performance assessment of EDR friction devices for the seismic rehabilitation of steel frames is investigated. Three steel Moment Resisting Frames (MRF's) with different numbers of stories are considered as the case studies. Double flag-shaped EDR devices are employed in order to improve the seismic response of the initial frames. The behavior of these dampers is highly nonlinear in comparison with other friction dampers. Accordingly, the improved ET method, which is based on nonlinear RPP spectra, is applied in order to satisfactorily estimate the responses in nonlinear range. From the results of this study, the following conclusions can be drawn:

1. In medium and large return periods, double flagshaped EDR devices effectively improve the seismic responses of the initial frames and reduce the demand parameters to acceptable codified values;

2. In small return periods, the seismic responses of the frames are not considerably improved. Therefore, if the initial frame significantly fails to satisfy performance limits corresponding to small return periods (for instance, the 72-yr return period), double flag-shaped EDR's cannot effectively mitigate the responses to reach the allowable limits;

3. As a result of the relatively small stiffness of the EDR's as well as the energy absorption due to their operation during the earthquake, the installation of the EDR devices does not significantly increase the absolute acceleration of stories compared to that of the initial structures; 

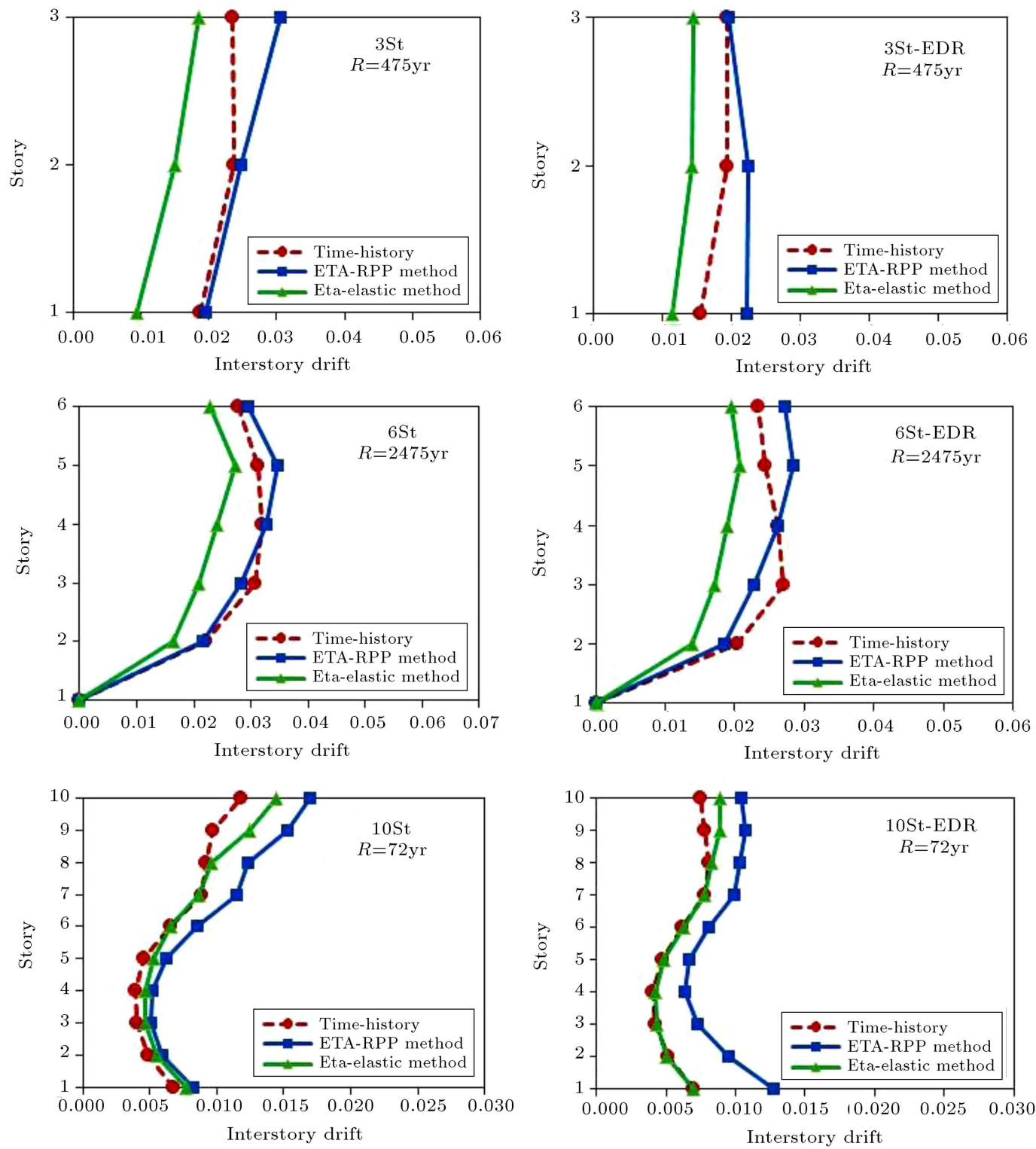

Figure 17. Comparison of the maximum interstory drift responses of the frames under study for a number of return periods calculated via time-history analysis, ET method based on RPP spectra, and ET method based on elastic spectra.

4. The application of the RPP spectra improves the accuracy and reliability of the response curves resulted from ET analysis in nonlinear range compared with the procedures based on linear elastic spectra. The results of the RPP spectra-based method show a reasonable concordance with the results of the time-history analysis.

As far as the computational cost is concerned, the ET method is far more economical in comparison with the conventional time-history method. Moreover, this method enjoys high reliability and accuracy compared to the alternate simplified methods and enables the evaluation of the seismic performance as a continuous function of seismic hazard return period. As a result, the ET method can effectively be employed for the multilevel performance-based seismic rehabilitation of structures.

Since friction is an effective, reliable, and economical mechanism which can dissipate the energy introduced to structures by seismic events, the use of this mechanism can be highly desirable in the seismic rehabilitation. The EDR is a self-centering friction device; thus, it can alleviate the permanent deformations of structures after the completion of the earthquake, leading to decreased damage repair costs. The hysteretic behavior of this device is highly nonlinear, so the use of the demanding nonlinear time-history analysis is requisite for the frames whose responses have been controlled through EDR devices. Applying the ET method can surmount the intricacy of the timeconsuming nonlinear time history analysis. In addition, 
it can place a more practical and favorable way at the disposal of structural designers in order to exploit the EDR friction mechanism for seismic hazard mitigation.

\section{References}

1. Cheng, F.Y., Jiang, H. and Lou, K., Smart Structures: Innovative Systems for Seismic Response Control, CRC Press, Taylor \& Francis Group (2008).

2. Soong, T.T. and Dargush, G.F., Passive Energy Dissipation Systems in Structural Engineering, John Wiley and Sons, New York (1997).

3. Pall, A.S., Marsh, C. and Fazio, P. "Friction joints for seismic control of large panel structures", Journal of Prestressed Concrete Institute, 25(6), pp. 38-61 (1980).

4. Pall, A.S. and Marsh, C. "Response of friction damped braced frames", Journal of Structural Division, ASCE, 108(9), pp. 1313-1323 (1982).

5. Aiken, I.D. and Kelly, J.M., Earthquake Simulator Testing and Analytical Studies of Two EnergyAbsorbing Systems for Multistory Structures, Report No. UCB/EERC-90/03, Earthquake Engineering Research Center, College of Engineering, University of California, Berkeley (1990).

6. Nims, D.K., Richter, P.J. and Bachman, R.E. "The use of the energy dissipating restraint for seismic hazard mitigation", Earthquake Spectra, 9(3), pp. 467-489 (1993).

7. FitzGerald, T.F., Anagnos, T., Goodson, M. and Zsutty, T. "Slotted bolted connections in aseismic design for concentrically braced connections", Earthquake Spectra, 5(2), pp. 383-391 (1989).

8. Richter, P.J., Nims, D.K., Kelly, J.M. and Kallenbach, R.M. "The EDR-energy dissipating restraint, a new device for mitigating seismic effects", Proceedings of the 1990 SEAOC Convention, 1, Lake Tahoe, pp. 377401 (1990).

9. Inaudi, J.A. and Kelly, J.M. "Dynamics of homogeneous frictional systems", Dynamics with Friction: Modeling, Analysis, and Experiments, 7, pp. 93-136 (1996).

10. Aiken, I.D., Nims, D.K., Whittaker, A.S. and Kelly, J.M. "Testing of passive energy dissipation systems", Earthquake Spectra, 9(3), pp. 335-370 (1993).

11. Inaudi, J.A. and Nicos, M. "Time-domain analysis of linear hysteretic damping", Earthquake Engineering and Structural Dynamics, 25, pp. 529-545 (1996).

12. Zhou, X. and Peng, L. "A new type of damper with friction-variable characteristics", Earthquake Engineering and Engineering Vibration, 8(4), pp. 507-520 (2009).

13. Nims, D.K., Inaudi, J.A., Richter, P.J. and Kelly, J.M. "Application of the energy dissipating restraint to buildings", Proceedings of ATC 17-1 on Seismic Isolation, Passive Energy Dissipation, and Active Control, 2, pp. 627-638 (1993).
14. Estekanchi, H.E., Vafai, A. and Sadeghazar, M. "Endurance time method for seismic analysis and design of structures", Scientia Iranica, 11(4), pp. 361-370 (2004).

15. Estekanchi, H.E., Valamanesh, V. and Vafai, A. "Application of endurance time method in linear seismic analysis", Engineering Structures, 29(10), pp. 25512562 (2007).

16. Nozari, A. and Estekanchi, H.E. "Optimization of endurance time acceleration functions for seismic assessment of structures", International Journal of Optimization in Civil Engineering, 1(2), pp. 257-277 (2011).

17. Basim M.Ch. and Estekanchi, H.E. "Application of endurance time method in performance-based optimum design of structures", Structural Safety, 56, pp. 52-67 (2015).

18. Mirzaee, A. and Estekanchi, H.E. "Performance-based seismic retrofitting of steel frames by endurance time method", Earthquake Spectra, 31(1), pp. 383-402 (2015).

19. Mirzaee, A., Estekanchi, H.E. and Vafai, A. "Improved methodology for endurance time analysis: From time to seismic hazard return period", Scientia Iranica, 19(5), pp. 1180-1187 (2012).

20. American Society of Civil Engineers (ASCE), Seismic Rehabilitation of Existing Buildings, ASCE/SEI 41-06, Reston, VA (2006).

21. Estekanchi, H.E., Riahi, H.T. and Vafai. A. "Application of endurance time method in seismic assessment of steel frames", Engineering Structures, 33, pp. 25352546 (2011).

22. Riahi, H.T., Estekanchi, H.E. and Vafai. A. "Estimates of average inelastic deformation demands for regular steel frames by the endurance time method", Scientia Iranica, 16(5), pp. 388-402 (2009).

23. Foyouzat, M.A. and Estekanchi, H.E. "Application of rigid-perfectly plastic spectra in improved seismic response assessment by endurance time method", Engineering Structures, 111, pp. 24-35 (2016).

24. Pacific Earthquake Engineering Research Center (PEERC) "Open system for earthquake engineering simulation", (OpenSees), University of California, Berkeley (2013). Online available at: http://OpenSees.berkeley.edu/

25. Foyouzat, M.A. "Evaluation of EDR performance in seismic control of steel structures using endurance time method", Thesis presented to the Sharif University of Technology in partial fulfillment of the requirements for the MS degree (2014).

26. Iranian National Building Code (INBC), Design and Construction of Steel Structures, Office of Collection and Extension of National Building Code, Ministry of Housing and Urban Development, Tehran, Iran (2005).

27. American Institute of Steel Construction (AISC), Manual of Steel Construction: Allowable Stress Design, 9th Edition, Chicago, USA (1989). 
28. Endurance Time Method website (2013).

https://sites.google.com/site/etmethod/

29. Elenas, A. and Meskouris, K. "Correlation study between seismic acceleration parameters and damage indices of structures", Engineering Structures, 23, pp. 698-704 (2001).

30. Connor, J.J., Introduction to Structural Motion Control, MIT/Prentice Hall (2002).

\section{Biographies}

Mohammad Ali Foyouzat received his BS and MS degrees in Civil Engineering from Sharif University of Technology, and is currently pursuing his $\mathrm{PhD}$ degree in Structural and Earthquake Engineering at the same university. He ranked first in the 17th National Civil
Engineering Olympiad, Iran, 2012. He has been a member of the Iranian National Elites Foundation since 2012. His research interests include structural control, performance-based design of structures, design of tall buildings, and analysis of plates and shells.

Homayoon Estekanchi is a professor of Civil Engineering at Sharif University of Technology (SUT). He received his PhD in Civil Engineering from SUT in 1997 and has been a faculty member at SUT since then. $\mathrm{He}$ is a member of Iranian Construction Engineers Organization, ASCE, Iranian Inventors Association, and several other professional associations. His research interests include a broad area of topics in structural and earthquake engineering with a special focus on the design of tall buildings and industrial structures. 